\title{
Nomogram to predict ypN status after chemoradiation in patients with locally advanced rectal cancer
}

\author{
E Jwa ${ }^{1}$, J H Kim ${ }^{*}, 1$ S Han ${ }^{2}$, J-h Park ${ }^{1}$, S-B Lim ${ }^{3}, \mathrm{~J} \mathrm{C} \mathrm{Kim}^{3}$, Y S Hong ${ }^{4}$, T W Kim ${ }^{4}$ and C S Yu ${ }^{3}$
}

${ }^{1}$ Department of Radiation Oncology, Asan Medical Center, University of Ulsan College of Medicine, Seoul 138-736, Republic of Korea; ${ }^{2}$ Department of Clinical Epidemiology and Biostatistics, Asan Medical Center, University of Ulsan College of Medicine, Seoul 138-736, Republic of Korea; ${ }^{3}$ Department of Surgery, Asan Medical Center, University of Ulsan College of Medicine, Seoul 138-736, Republic of Korea and ${ }^{4}$ Department of Oncology, Asan Medical Center, University of Ulsan College of Medicine, Seoul 138-736, Republic of Korea

Background: Pelvic lymph node (LN) status after preoperative chemoradiotherapy (CRT) is an important indicator of oncologic outcome in patients with locally advanced rectal cancer. The purpose of this study was to develop a nomogram to predict $L N$ status after preoperative CRT in locally advanced rectal cancer patients.

Methods: The nomogram was developed in a training cohort $(n=891)$ using logistic regression analyses and validated in a validation cohort $(n=258)$ from a prospectively registered tumour registry at Asan Medical Center. The model was internally and externally validated for discrimination and calibration using bootstrap resampling. Model performance was evaluated by the concordance index (c-index) and calibration curve.

Results: Pretreatment ypT stage, patient age, preCRT tumour differentiation, cN stage, lymphovascular invasion, and perineural invasion were reliable predictors of $L N$ metastasis after preoperative CRT. The nomogram developed using these parameters had c-indices of 0.81 (training) and 0.77 (validation). The calibration plot suggested good agreement between actual and nomogrampredicted LN status after preoperative CRT.

Conclusions: This nomogram improves prediction of LN status after preoperative CRT in patients with locally advanced rectal cancer. It will be useful for counselling patients as well as for the design and stratification of patients in clinical trials.

Preoperative chemoradiotherapy (CRT) followed by total mesorectal excision (TME) is the current standard of care for locally advanced rectal cancer to achieve better local control and overall survival (Sauer et al, 2004; Folkesson et al, 2005; Park et al, 2011). The potential advantages of preoperative CRT are both downsizing and downstaging of the tumour. Approximately $8-25 \%$ of patients have pathologic complete response (pCR) after preoperative CRT (Sauer et al, 2004; Shivnani et al, 2007; Park et al, 2011), and this pCR is associated with favourable treatment outcome (Maas et al, 2010). Increasing data suggest that the downsizing and downstaging effect of preoperative CRT may warrant expansion of the applicability of local excision to more advanced tumours (Borschitz et al, 2008; Callender et al, 2010; Belluco et al, 2011; Bujko et al, 2013). The rationale for performing local excision is based on the assumption that mesorectal lymph nodes (LNs) are completely eradicated and that the risk of residual disease in the mesorectum is very low. Therefore, accurate preoperative assessment of LN status after CRT is crucial for planning optimal therapy. However, the accuracy of current clinical imaging modalities in restaging LN status after CRT is limited (Cho et al, 2009; Pomerri et al, 2011).

To the best of our knowledge, the clinical predictors of LN status after preoperative CRT remain largely unknown. Some

*Correspondence: Dr JH Kim; E-mail: jhkim2@amc.seoul.kr

This work was presented in part at the Annual ASCO Gastrointestinal Cancers Symposium, January 24-26, 2013, San Francisco, CA, USA.

Received 2 January 2014; revised 10 April 2014; accepted 13 April 2014; published online 26 June 2014

(c) 2014 Cancer Research UK. All rights reserved 0007-0920/14 
retrospective studies on the clinical predictors of LN status reported inconsistent and equivocal results (Pucciarelli et al, 2005; Hughes et al, 2006; Das et al, 2007; Cho et al, 2009; Chen et al, 2012). To overcome the inaccuracies of current diagnostic modalities for restaging after preoperative CRT in rectal cancer patients, a model that accurately predicts the postCRT LN status on the basis of each patient's overall characteristics, rather than a single parameter, is needed. The purpose of the present study was to investigate the predictive factors for LN status after preoperative CRT and to develop a nomogram using these factors to predict LN status in patients who underwent preoperative CRT for rectal cancer.

\section{MATERIALS AND METHODS}

Study Population. This study was approved by the institutional review board of Asan Medical Center (AMC). The study cohort was created from a prospectively maintained tumour registry of the Department of Radiation Oncology at AMC. Using the registry, we identified a total of 1166 patients who underwent preoperative CRT followed by TME at AMC for non-metastatic rectal adenocarcinoma, including mucinous or signet ring cell type between 2007 and 2013. Because we believed radiation dose under $40 \mathrm{~Gy}$ was insufficient to treat metastatic regional $\mathrm{LN}$, patients who received doses of less than $40 \mathrm{~Gy}(n=17)$ were excluded. Most patients had locally advanced disease (cT3 or cT4 or positive regional LN) on endorectal ultrasonography (EUS), magnetic resonance imaging (MRI), or abdominopelvic computed tomography (CT) scan; however, seven patients had cT2N0 distal rectal cancer. Patients were divided into the nomogram development $(n=891)$ or the validation $(n=258)$ cohort according to treatment time, that is, from 2007 to 2011 and from 2012 to 2013, respectively. All the development and the validation cohort patients were treated with three-dimensional conformal radiotherapy with a fraction size of $1.8-2 \mathrm{~Gy}$, except the 17 patients who underwent intensity modulated radiotherapy. The median total dose was 50 Gy (range, 40-55 Gy), including up to 46 Gy to the whole pelvis. Preoperative chemotherapy was administered concurrently with radiation in all patients except for three in the development cohort. The concurrent chemotherapy regimen was capecitabine in 415 (36.1\%), 5-FU with leucovorin in 664 (57.8\%), and other drug added to capecitabine or 5-FU in 67 $(5.8 \%)$ patients. The median interval period between CRT and surgery was 6.4 weeks (range, 3.0-19.4 weeks). The sphincter was spared in 875 patients $(76.2 \%)$, while it was not spared in 274 patients (23.8\%). The median number of harvested LNs was 16 (range, 1-68). All surgical specimens were processed according to standard procedures at AMC. Tumour regression grade was microscopically evaluated using the scale proposed by Dworak et al (1997) Each patient was clinically and pathologically staged according to the 2010 American Joint Committee on Cancer (AJCC) staging classification system (AJCC, 2010). Tumour grade was assessed according to the 2000 World Health Organization criteria (Hosmer and Lemeshow, 2000).

Statistical analysis. The primary end point of interest in this study was the presence or absence of pathologic LN metastasis (ypN) after preoperative CRT, which was determined by the assessment of pathologic specimen obtained from curative surgery. Multivariate regression analysis was performed using a logistic regression model, and this model formed the basis for the ypN prediction model. The potential predictors for ypN status analysed in this study included age, gender, chemotherapy regimen, radiation dose, interval period between radiation and surgery, distance from anal verge, $\mathrm{cT}$ stage, $\mathrm{cN}$ stage, preCRT tumour differentiation, preCRT CEA level, postCRT CEA level, ypT stage, perineural invasion, lymphovascular invasion, and tumour regression grade. An initial univariate logistic regression model was fitted to evaluate the prognostic value of each variable. To select variables for the final multivariate model, we resorted to the bootstrapping resampling method (500 repetitions), which determines the predictive robustness of candidate variables. A 50\% relative frequency of selection and clinical relevance were the criteria for the inclusion of variables in the final model. Selection of the final model was based on the method described by Jin et al (2012). The prediction model was implemented into a nomogram to be applicable on plain paper. The discrimination and calibration abilities of the prognostic model were measured by receiver operating characteristic techniques and the Hosmer-Lemeshow test, respectively (Hanley and McNeil, 1982; Hosmer and Lemeshow, 2000). Discrimination was evaluated using the concordance index (c-index), which measures the probability that, given a pair of randomly selected patients, the model correctly predicts which patient will experience an event first. The c-index of the model can range between 0.5 , which represents random chance, and 1.0, which represents a perfectly discriminating model (Harrell et al, 1982). The second validation measure evaluated was calibration, which compares the predicted LN metastasis probability with actual LN metastasis. This was evaluated with a calibration curve, where patients are grouped by predicted node metastasis and then plotted as actual vs predicted LN metastasis. Both discrimination and calibration were evaluated in the development and the validation cohort, respectively. All statistical analyses were performed using SPSS version 13.0 (SPSS, Chicago, IL, USA) and R software version 2.12.0 (http://www.r-project.org/), with an optional package installed, called rms (Harrell, 2012). In addition, $\mathrm{R}$ package of survival (available at http://cran. r-project.org/web/packages/) was used in this study.

\section{RESULTS}

The clinical and pathologic characteristics of patients in both cohorts are listed in Table 1. Median age at diagnosis was 58 (range, 25-82 years) in the nomogram development cohort and 61 (range, 28-83 years) in the external validation cohort. There were $599(67.2 \%)$ and 167 (64.7\%) male patients in the development and the validation cohort, respectively. Pathology analysis of surgical specimens showed that 307 (26.7\%) patients had LNs harbouring tumour cells. The risk for $\mathrm{LN}$ involvement increased with advancing grade of remaining mural tumour; positive LNs were detected in 16 of the $204(7.8 \%)$ ypT0 patients, in three of the 26 (11.5\%) ypTis patients, in six of the $64(9.4 \%)$ ypT1 patients, in 53 of the $310(17.1 \%)$ ypT2 patients, in 226 of the $528(42.8 \%)$ ypT3 patients, and in three of the $13(23.1 \%)$ ypT4 patients in both cohorts collectively. The results of the univariate and the multivariate regression analysis models are shown in Table 2. In univariate analysis, younger age, $\mathrm{cN}$ stage, preCRT tumour differentiation, ypT stage, lymphovascular invasion, perineural invasion, and tumour regression grade were significant predictors of pathologic LN metastasis. Six variables, including patient age, $\mathrm{cN}$ stage, preCRT tumour differentiation, ypT stage, lymphovascular invasion, and perineural invasion, showed relative frequencies $>50 \%$ by the bootstrapping method. When applied to the multivariable model, these six covariates were found to be significant. A nomogram predicting the pathologic LN metastasis was constructed with these six parameters including three determined before CRT and three determined after CRT based on the multivariable model (Figure 1). To use the nomogram, a vertical line is drawn up to the top point row to assign points for each variable. Then, the total number of points is calculated, and a 


\section{Table 1. Clinical characteristics of 1149 patients undergoing TME after preoperative CRT}

\begin{tabular}{|c|c|c|c|c|c|}
\hline & \multicolumn{2}{|c|}{ Development $(n=891)$} & \multicolumn{2}{|c|}{ Validate $(n=258)$} & \multirow[b]{2}{*}{$P$-value } \\
\hline & No. of patients & $\%$ & No. of patients & $\%$ & \\
\hline Tumour location (cm), median (range) & $5(0-15)$ & & $4(0-13)$ & & 0.002 \\
\hline Initial CEA & $2.6(0.3-345.0)$ & & $2.4(0.3-124.0)$ & & 0.342 \\
\hline Initial tumour differentiation & & & & & 0.172 \\
\hline $\begin{array}{l}\text { Well or moderate } \\
\text { Poor, mucinous, or signet ring cell }\end{array}$ & $\begin{array}{r}782 \\
63\end{array}$ & $\begin{array}{r}87.8 \\
7.1\end{array}$ & $\begin{array}{r}245 \\
11\end{array}$ & $\begin{array}{r}95.0 \\
4.3\end{array}$ & \\
\hline cT stage & & & & & 0.475 \\
\hline $\begin{array}{l}\text { T2 } \\
\text { T3 } \\
\text { T4 }\end{array}$ & $\begin{array}{r}19 \\
694 \\
178\end{array}$ & $\begin{array}{r}2.1 \\
77.9 \\
20.0\end{array}$ & $\begin{array}{r}5 \\
210 \\
43\end{array}$ & $\begin{array}{r}1.9 \\
81.4 \\
16.7\end{array}$ & \\
\hline $\mathrm{cN}$ stage & & & & & 0.001 \\
\hline $\begin{array}{l}\text { N0 } \\
\text { N1 } \\
\text { N2 }\end{array}$ & $\begin{array}{r}25 \\
200 \\
666\end{array}$ & $\begin{array}{r}2.8 \\
22.4 \\
74.7\end{array}$ & $\begin{array}{r}18 \\
71 \\
169\end{array}$ & $\begin{array}{r}7.0 \\
27.5 \\
65.5\end{array}$ & \\
\hline cAJCC stage & & & & & 0.005 \\
\hline $\begin{array}{l}\text { I } \\
\text { II } \\
\text { III }\end{array}$ & $\begin{array}{r}3 \\
22 \\
866\end{array}$ & $\begin{array}{r}0.3 \\
2.5 \\
97.2\end{array}$ & $\begin{array}{r}4 \\
14 \\
240\end{array}$ & $\begin{array}{r}1.6 \\
5.4 \\
93.0\end{array}$ & \\
\hline Tumour regression grade & & & & & 0.636 \\
\hline $\begin{array}{l}\text { Total } \\
\text { Near total } \\
\text { Moderate } \\
\text { Minimal }\end{array}$ & $\begin{array}{l}162 \\
203 \\
404 \\
122\end{array}$ & $\begin{array}{l}18.2 \\
22.8 \\
45.3 \\
13.7\end{array}$ & $\begin{array}{r}45 \\
52 \\
118 \\
42\end{array}$ & $\begin{array}{l}17.4 \\
20.2 \\
45.7 \\
16.3\end{array}$ & \\
\hline ypT stage & & & & & 0.791 \\
\hline $\begin{array}{l}\text { Tx } \\
\text { Tis } \\
\text { T1 } \\
\text { T2 } \\
\text { T3 } \\
\text { T4 }\end{array}$ & $\begin{array}{r}160 \\
22 \\
53 \\
235 \\
409 \\
10\end{array}$ & $\begin{array}{r}18.0 \\
2.5 \\
5.9 \\
26.4 \\
45.9 \\
1.1\end{array}$ & $\begin{array}{r}45 \\
5 \\
11 \\
75 \\
119 \\
3\end{array}$ & $\begin{array}{r}17.4 \\
1.9 \\
4.3 \\
29.1 \\
46.1 \\
1.2\end{array}$ & \\
\hline ypN stage & & & & & 0.270 \\
\hline $\begin{array}{l}\text { N0 } \\
\text { N1 } \\
\text { N2 }\end{array}$ & $\begin{array}{r}643 \\
192 \\
56\end{array}$ & $\begin{array}{r}72.2 \\
21.5 \\
6.3\end{array}$ & $\begin{array}{r}198 \\
44 \\
15\end{array}$ & $\begin{array}{r}76.7 \\
17.1 \\
5.8\end{array}$ & \\
\hline Lymphovascular invasion & 73 & 8.2 & 24 & 9.3 & 0.610 \\
\hline Perineural invasion & 136 & 15.3 & 24 & 9.3 & 0.014 \\
\hline
\end{tabular}

vertical line is drawn downwards from the total point row to obtain the probability of positive LN. For example, patients with 90, 176, and 228 points had estimated positive LN probability of $10 \%, 50 \%$, and $80 \%$, respectively. The predictive accuracy measured by the c-index was 0.81 . The nomogram was well calibrated, and there was good correlation and no deviation between predicted and observed outcome across the spectrum of predictions (Figure 2A). In the external validation cohort $(n=258)$, the accuracy of the model was 0.77 . Calibration plots of the nomogram-predicted probabilities and the actual number of LN metastasis in the external cohort are displayed in Figure 2B.

\section{DISCUSSION}

The present study demonstrates that ypT stage, age, preCRT tumour differentiation, $\mathrm{cN}$ stage, lymphovascular invasion, and perineural invasion (in order of relevance) are reliable predictors for LN metastasis after preoperative CRT in patients with locally advanced rectal cancer. To predict the risk of residual LN metastasis after CRT, we used these predictors to develop a nomogram with a continuous scale and a discriminative accuracy of 0.81 . When validated in an independent population, this nomogram provided good discrimination with a c-index of 0.77 for predicting postCRT LN metastasis.

Several studies have investigated full-thickness transanal local excision as a primary treatment for selected patients with clinical stage I rectal cancers to avoid postoperative complications and unsatisfactory functional outcomes following TME (Rutten et al, 2008; Greenberg et al, 2008; Paun et al, 2010). The tumour downstaging effect of preoperative CRT observed in both primary tumour and mesorectal metastatic LNs results in a ypCR rate of up to $25 \%$ in locally advanced rectal cancer patients (Shivnani et al, 2007). In addition, patients who achieve ypCR after CRT have more favourable long-term outcome (Maas et al, 2010). In view of these data, local excision has been considered for a subset of 


\begin{tabular}{|c|c|c|c|c|c|c|}
\hline & \multicolumn{3}{|c|}{ Univariate analysis } & \multicolumn{3}{|c|}{ Multivariate analysis } \\
\hline & OR & $95 \% \mathrm{Cl}$ & $P$-value & OR & $95 \% \mathrm{Cl}$ & $P$-value \\
\hline Age & 0.98 & $0.96-0.99$ & 0.001 & 0.98 & $0.96-0.99$ & 0.003 \\
\hline Female & 1.18 & $0.87-1.61$ & 0.284 & & & \\
\hline Poorly differentiated, mucinous, and signet ring cell & 2.19 & $1.30-3.70$ & 0.003 & 3.29 & $1.78-6.11$ & 0.000 \\
\hline \multicolumn{7}{|l|}{ cT stage } \\
\hline $\begin{array}{l}\text { T2 } \\
\text { T3 } \\
\text { T4 }\end{array}$ & $\begin{array}{l}1.00 \\
3.37 \\
3.23\end{array}$ & $\begin{array}{c}\text { Referent } \\
0.77-14.72 \\
0.72-14.49\end{array}$ & $\begin{array}{c}-\overline{1106} \\
0.126\end{array}$ & $\begin{array}{l}- \\
- \\
-\end{array}$ & $\begin{array}{l}- \\
- \\
-\end{array}$ & $\begin{array}{l}- \\
- \\
-\end{array}$ \\
\hline \multicolumn{7}{|l|}{ cN stage } \\
\hline $\begin{array}{l}\text { N0 } \\
\text { N1 } \\
\text { N2 }\end{array}$ & $\begin{array}{l}1.00 \\
2.04 \\
2.44\end{array}$ & $\begin{array}{c}\text { Referent } \\
1.33-3.22 \\
1.83-7.18\end{array}$ & $\begin{array}{c}- \\
0.001 \\
0.000\end{array}$ & $\begin{array}{l}1.77 \\
- \\
-\end{array}$ & $\begin{array}{c}1.21-2.61 \\
- \\
-\end{array}$ & $\begin{array}{c}0.004 \\
- \\
-\end{array}$ \\
\hline \multicolumn{7}{|l|}{ урT stage } \\
\hline $\begin{array}{l}\text { T0 } \\
\text { Tis } \\
\text { T1 } \\
\text { T2 } \\
\text { T3 } \\
\text { T4 }\end{array}$ & $\begin{array}{l}1.00 \\
0.46 \\
1.23 \\
2.10 \\
7.67 \\
4.14\end{array}$ & $\begin{array}{c}\text { Referent } \\
0.06-3.67 \\
0.45-3.36 \\
1.12-3.94 \\
4.36-13.52 \\
0.97-17.72\end{array}$ & $\begin{array}{c}- \\
0.464 \\
0.681 \\
0.020 \\
0.000 \\
0.055\end{array}$ & $\begin{array}{l}1.68 \\
- \\
- \\
- \\
- \\
-\end{array}$ & $\begin{array}{c}1.43-1.97 \\
- \\
- \\
- \\
- \\
-\end{array}$ & $\begin{array}{c}0.000 \\
- \\
- \\
- \\
- \\
-\end{array}$ \\
\hline Lymphovascular invasion & 3.78 & $2.32-6.16$ & 0.000 & 2.24 & $1.31-3.84$ & 0.003 \\
\hline Perineural invasion & 3.69 & $2.53-5.38$ & 0.000 & 1.87 & $1.22-2.85$ & 0.004 \\
\hline \multicolumn{7}{|l|}{ Tumour regression grade } \\
\hline $\begin{array}{l}\text { Total } \\
\text { Near total } \\
\text { Moderate } \\
\text { Minimal }\end{array}$ & $\begin{array}{l}1.00 \\
2.79 \\
5.37 \\
5.73\end{array}$ & $\begin{array}{c}\text { Referent } \\
1.49-5.22 \\
3.04-9.49 \\
3.00-10.93\end{array}$ & $\begin{array}{c}- \\
0.001 \\
0.000 \\
0.000\end{array}$ & $\begin{array}{c}0.45 \\
- \\
- \\
-\end{array}$ & $\begin{array}{c}0.15-1.70 \\
- \\
- \\
-\end{array}$ & $\begin{array}{c}0.149 \\
- \\
- \\
-\end{array}$ \\
\hline PreRT CEA & 1.00 & $1.00-1.01$ & 0.419 & - & - & - \\
\hline PostRT CEA & 1.00 & $0.99-1.01$ & 0.857 & - & - & - \\
\hline RT dose & 0.97 & $0.83-1.14$ & 0.701 & - & - & - \\
\hline RT-surgery interval duration & 1.05 & $0.94-1.17$ & 0.375 & - & - & - \\
\hline Distance from anal verge & 1.05 & $0.99-1.10$ & 0.086 & - & - & - \\
\hline \multicolumn{7}{|l|}{ Chemotherapy regimen } \\
\hline $\begin{array}{l}\text { Capecitabine } \\
\text { FL } \\
\text { Others }\end{array}$ & $\begin{array}{l}1.00 \\
1.32 \\
1.06 \\
\end{array}$ & $\begin{array}{c}\text { Referent } \\
0.97-1.79 \\
0.58-1.94\end{array}$ & $\begin{array}{c}-\overline{0} \\
0.081 \\
0.843\end{array}$ & $\begin{array}{l}- \\
- \\
-\end{array}$ & $\begin{array}{l}- \\
- \\
-\end{array}$ & - \\
\hline
\end{tabular}

patients with locally advanced rectal cancer and good response after CRT (Borschitz et al, 2008; Callender et al, 2010; Belluco et al, 2011; Bujko et al, 2013). However, from an oncologic point of view, local excision after preoperative CRT has the risk of leaving nodal disease in the mesorectum. Therefore, it is important to restage accurately after CRT, particularly to rule out any residual cancer in the mesorectum. However, the most commonly used imaging modalities, such as EUS, MRI, and CT scanning, or additional diagnostic tools such as FDG-PET scanning for initial staging of rectal cancer, have a limited accuracy of $62-75 \%$ to identify regional LN metastases after preoperative CRT (Cho et al, 2009; Pomerri et al, 2011). Post-irradiation inflammatory or desmoplastic changes, as well as controversy over which criteria to use (i.e., size $v s$ morphology), for predicting metastatic LN make the diagnosis of postCRT LN status difficult.
Several studies investigated the predictive factors for ypN status, but results are inconsistent. Whether the ypT classification correlates with LN status or any other predictive parameters for postCRT LN status in rectal cancer patients treated with preoperative CRT remains under debate (Pucciarelli et al, 2005; Hughes et al, 2006; Cho et al, 2009). The rate of LN metastasis with no residual mural tumour (ypT0N + ) after preoperative CRT has been reported to be up to $17 \%$ (Pucciarelli et al, 2005). While Glynne-Jones et al (Hughes et al, 2006) failed to show predictive value of ypT, Pucciarelli et al (2005) reported consistent results to that of the current paper that ypT, young age, and positive pretreatment nodal status are predictors for postCRT LN metastasis.

Biologic responses and compliance to cancer treatment seem to change with age: elderly patients show a lower rate of postCRT 


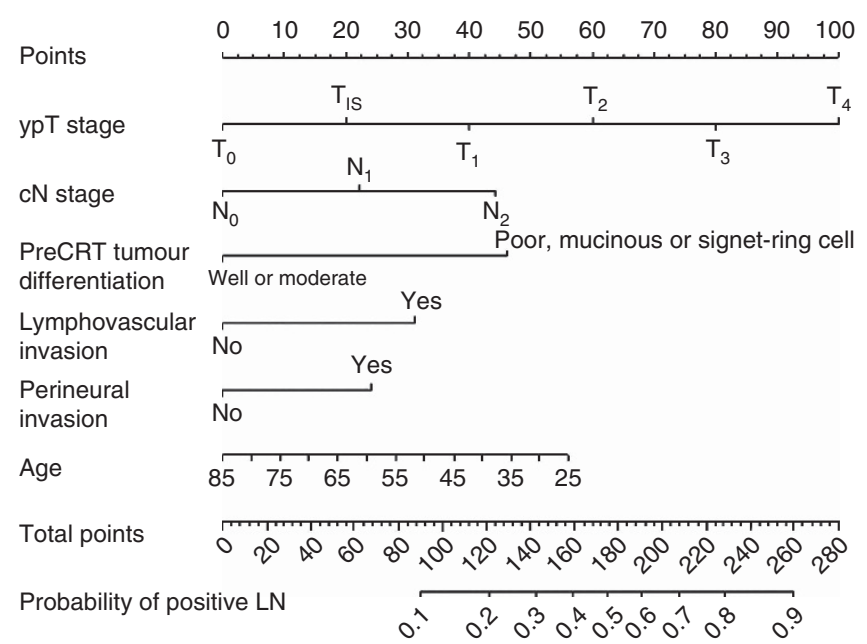

Figure 1. Nomogram predicting LN metastasis probability after preoperative CRT for locally advanced rectal cancer. Each variable value is assigned a point, and the sum of points is converted to a probability in the lowest scale.

LN metastasis than younger patients, although Steinhagen et al (2013) reported similar rates of response to neoadjuvant CRT in patients with early-age-onset rectal cancer and in non-age-based cohorts. Understanding this difference warrants further investigation. Kim et al (Cho et al, 2009) also examined the correlation between postCRT LN status and tumour regression grade, but found that only patients with complete regression were associated with a low incidence of LN metastasis. Therefore, the authors concluded the pathologic regression grade does not demonstrate any additional benefit over the ypT classification. Similarly, only complete tumour regression could predict the postCRT LN status, while other levels of tumour regression had no correlation with ypN status in our analysis. Besides these clinical parameters, Chen et al (2012) reported that chromosomal copy number alterations could help identify rectal cancer patients at risk of LN metastasis after preoperative CRT with $86 \%$ of accuracy. Some studies suggested different cut-off values of CEA as a predictor for tumour response to neoadjuvant CRT (Yoon et al, 2007; Park et al, 2009). We analysed serum CEA as a continuous variable instead of dichotomous variable, because the cut-off value could be somewhat arbitrary and consequentially reduce predictive accuracy. However, the current study failed to demonstrate the predictive value of CEA level based on continuous scale before or after CRT.

There are potential applications for this nomogram. First, it may act as a tool to assist both physicians and patients in treatment selection. For example, a reliable predictor of treatment outcome based both on this nomogram and on the results of conventional imaging modalities, such as EUS, MRI, or CT, may help a patient decide whether to undergo local excision after preoperative CRT. If the patient is at high risk of $\mathrm{LN}$ metastasis after local excision, clinicians should consider radical surgery. In addition, when local excision is inevitable due to patient comorbidity or strong refusal of expected stoma, risk appraisal of residual $\mathrm{LN}$ in mesorectum could help determine the follow-up schedule or use of adjuvant chemotherapy. The nomogram may also be valuable in the design of clinical trials. As further evidence for local excision after preoperative CRT should be generated from randomised control trials, this nomogram could help to identify patients most likely to benefit from local excision by quantifying the probability of postCRT LN metastasis. Selection of candidates and verification of adequate randomisation would be facilitated by comprehensive risk
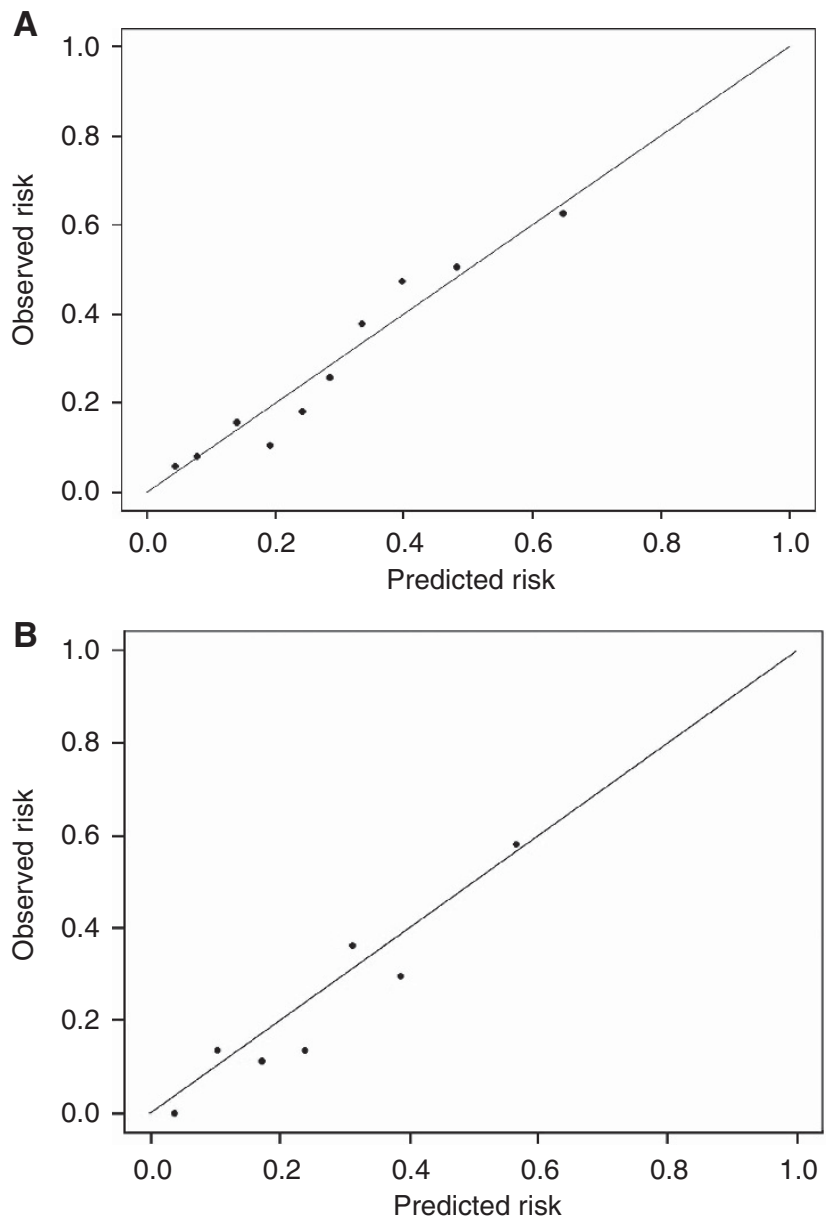

Figure 2. Calibration plots in the internal validation cohort (A) and the external validation cohort (B). The solid line indicates a reference line where an ideal nomogram would lie. Dots indicate the performance of the current nomogram.

estimation rather than comparing individual predictors, which may not as easily produce homogenous groups of patients. The nomogram is also useful to visualise the associations between each predictor variable and the risk of LN metastasis. Because this tool considers multiple predictive factors simultaneously, including continuous values, more complex relationships between known predictors of ypN status can be assessed.

The present study has several limitations. The major limitation is that this nomogram is based on a retrospective analysis of our database. In addition, its applicability to the general population requires further testing despite our external validation. However, the current cohort of patients was derived from a single institution's homogenous population and the management protocols for locally advanced rectal cancer including surgery, radiotherapy, pathologic review, and diagnostic work-up were consistent during the study period, indicating that this nomogram is a reliable reference that can be used for further investigation. The current nomogram merely predicts LN metastasis probability but not longterm clinical outcomes (i.e., local recurrence and disease-free survival). Physicians and patients should be cautious when deciding between local excision and radical surgery following preoperative CRT, especially in good responders.

We need to further test our model performance by external validation using other patient databases. Other regression modelling techniques should also be explored to determine whether predictive accuracy can be further improved. If more specific patient and tumour information, such as genetic data and 
molecular tumour markers, become routinely available in the future, use of these types of predictive models will become more specific and valuable.

In conclusion, we present a prediction model for LN metastasis that can be used to determine individualised treatment choices after preoperative CRT in patients with locally advanced rectal cancer. Our model predicts that patients with low $\mathrm{cN}$ stage and well to moderately differentiated non-metastatic rectal adenocarcinoma downstaged to ypT0-1 without perineural or lymphovascular invasion after preoperative CRT have a low likelihood of positive LN, when preoperative imaging studies show no metastatic LN after preoperative CRT. The nomogram can assist clinicians and patients in quantifying the benefit of curative surgery compared with local excision after preoperative CRT for rectal cancer.

\section{CONFLICT OF INTEREST}

The authors declare no conflict of interest.

\section{REFERENCES}

AJCC (2010) AJCC Cancer Staging Manual. In Edge S, Byrd DR, Compton CC, Fritz AG, Greene FL, Torotti A (eds) 7th edn. Springer-Verlag: New York, NY.

Belluco C, De Paoli A, Canzonieri V, Sigon R, Fornasarig M, Buonadonna A, Boz G, Innocente R, Perin T, Cossaro M, Polesel J, De Marchi F (2011) Long-term outcome of patients with complete pathologic response after neoadjuvant chemoradiation for $\mathrm{cT} 3$ rectal cancer: implications for local excision surgical strategies. Ann Surg Oncol 18: 3686-3693.

Borschitz T, Wachtlin D, Mohler M, Schmidberger H, Junginger T (2008) Neoadjuvant chemoradiation and local excision for T2-3 rectal cancer. Ann Surg Oncol 15: 712-720.

Bujko K, Richter P, Smith FM, Polkowski W, Szczepkowski M, Rutkowski A, Dziki A, Pietrzak L, Kolodziejczyk M, Kusnierz J, Gach T, Kulig J, Nawrocki G, Radziszewski J, Wierzbicki R, Kowalska T, Meissner W, Radkowski A, Paprota K, Polkowski M, Rychter A (2013) Preoperative radiotherapy and local excision of rectal cancer with immediate radical reoperation for poor responders: a prospective multicentre study. Radiother Oncol 106: 198-205.

Callender GG, Das P, Rodriguez-Bigas MA, Skibber JM, Crane CH, Krishnan S, Delclos ME, Feig BW (2010) Local excision after preoperative chemoradiation results in an equivalent outcome to total mesorectal excision in selected patients with T3 rectal cancer. Ann Surg Oncol 17: $441-447$.

Chen Z, Liu Z, Deng X, Warden C, Li W, Garcia-Aguilar J (2012) Chromosomal copy number alterations are associated with persistent lymph node metastasis after chemoradiation in locally advanced rectal cancer. Dis Colon Rectum 55: 677-685.

Cho YB, Chun HK, Kim MJ, Choi JY, Park CM, Kim BT, Lee SJ, Yun SH, Kim HC, Lee WY (2009) Accuracy of MRI and 18F-FDG PET/CT for restaging after preoperative concurrent chemoradiotherapy for rectal cancer. World J Surg 33: 2688-2694.

Das P, Skibber JM, Rodriguez-Bigas MA, Feig BW, Chang GJ, Wolff RA, Eng C, Krishnan S, Janjan NA, Crane CH (2007) Predictors of tumor response and downstaging in patients who receive preoperative chemoradiation for rectal cancer. Cancer 109: 1750-1755.

Dworak O, Keilholz L, Hoffmann A (1997) Pathological features of rectal cancer after preoperative radiochemotherapy. Int $J$ Colorectal Dis 12: $19-23$.

Folkesson J, Birgisson H, Pahlman L, Cedermark B, Glimelius B, Gunnarsson U (2005) Swedish Rectal Cancer Trial: long lasting benefits from radiotherapy on survival and local recurrence rate. J Clin Oncol 23: 5644-5650.

Greenberg JA, Shibata D, Herndon 2nd JE, Steele Jr GD, Mayer R, Bleday R (2008) Local excision of distal rectal cancer: an update of cancer and leukemia group B 8984. Dis Colon Rectum 51: 1185-1191.
Hanley JA, McNeil BJ (1982) The meaning and use of the area under a receiver operating characteristic (ROC) curve. Radiology 143: 29-36.

Harrell FE (2012) rms: Regression Modeling Strategies. R package version 3.5-0. (Computer Program) http://CRAN.R-project.org/package=rms.

Harrell Jr FE, Califf RM, Pryor DB, Lee KL, Rosati RA (1982) Evaluating the yield of medical tests. JAMA 247: 2543-2546.

Hosmer DW, Lemeshow S (2000) Applied Logistic Regression. 2nd edn. Wiley: New York.

Hughes R, Glynne-Jones R, Grainger J, Richman P, Makris A, Harrison M, Ashford R, Harrison RA, Livingstone JI, McDonald PJ, Meyrick Thomas J, Mitchell IC, Northover JM, Phillips R, Wallace M, Windsor A, Novell JR (2006) Can pathological complete response in the primary tumour following pre-operative pelvic chemoradiotherapy for T3-T4 rectal cancer predict for sterilisation of pelvic lymph nodes, a low risk of local recurrence and the appropriateness of local excision? Int J Colorectal Dis 21: 11-17.

Jin YJ, Lim YS, Han S, Lee HC, Hwang S, Lee SG (2012) Predicting survival after living and deceased donor liver transplantation in adult patients with acute liver failure. J Gastroenterol 47: 1115-1124.

Maas M, Nelemans PJ, Valentini V, Das P, Rodel C, Kuo LJ, Calvo FA, Garcia-Aguilar J, Glynne-Jones R, Haustermans K, Mohiuddin M, Pucciarelli S, Small Jr W, Suarez J, Theodoropoulos G, Biondo S, Beets-Tan RG, Beets GL (2010) Long-term outcome in patients with a pathological complete response after chemoradiation for rectal cancer: a pooled analysis of individual patient data. Lancet Oncol 11: 835-844.

Park JH, Yoon SM, Yu CS, Kim JH, Kim TW, Kim JC (2011) Randomized phase 3 trial comparing preoperative and postoperative chemoradiotherapy with capecitabine for locally advanced rectal cancer. Cancer 117: 3703-3712.

Park JW, Lim SB, Kim DY, Jung KH, Hong YS, Chang HJ, Choi HS, Jeong SY (2009) Carcinoembryonic antigen as a predictor of pathologic response and a prognostic factor in locally advanced rectal cancer patients treated with preoperative chemoradiotherapy and surgery. Int J Radiat Oncol Biol Phys 74: 810-817.

Paun BC, Cassie S, MacLean AR, Dixon E, Buie WD (2010) Postoperative complications following surgery for rectal cancer. Ann Surg 251: 807-818.

Pomerri F, Pucciarelli S, Maretto I, Zandona M, Del Bianco P, Amadio L, Rugge M, Nitti D, Muzzio PC (2011) Prospective assessment of imaging after preoperative chemoradiotherapy for rectal cancer. Surgery 149: 56-64.

Pucciarelli S, Capirci C, Emanuele U, Toppan P, Friso ML, Pennelli GM, Crepaldi G, Pasetto L, Nitti D, Lise M (2005) Relationship between pathologic T-stage and nodal metastasis after preoperative chemoradiotherapy for locally advanced rectal cancer. Ann Surg Oncol 12: 111-116.

Rutten HJ, den Dulk M, Lemmens VE, van de Velde CJ, Marijnen CA (2008) Controversies of total mesorectal excision for rectal cancer in elderly patients. Lancet Oncol 9: 494-501.

Sauer R, Becker H, Hohenberger W, Rodel C, Wittekind C, Fietkau R, Martus P, Tschmelitsch J, Hager E, Hess CF, Karstens JH, Liersch T, Schmidberger H, Raab R. German Rectal Cancer Study G (2004) Preoperative $v s$ postoperative chemoradiotherapy for rectal cancer. $N$ Engl J Med 351: 1731-1740.

Shivnani AT, Small Jr W, Stryker SJ, Kiel KD, Lim S, Halverson AL, Talamonti MS (2007) Preoperative chemoradiation for rectal cancer: results of multimodality management and analysis of prognostic factors. Am J Surg 193: 389-393.

Steinhagen E, Shia J, Riedel E, Nash GM, Weiser MR, Temple LK, Paty PB, Guillem JG (2013) Response to neoadjuvant therapy in patients with early age-of-onset rectal cancer. Dis Colon Rectum 56: $58-63$.

Yoon SM, Kim DY, Kim TH, Jung KH, Chang HJ, Koom WS, Lim SB, Choi HS, Jeong SY, Park JG (2007) Clinical parameters predicting pathologic tumor response after preoperative chemoradiotherapy for rectal cancer. Int J Radiat Oncol Biol Phys 69: 1167-1172.

This work is published under the standard license to publish agreement. After 12 months the work will become freely available and the license terms will switch to a Creative Commons AttributionNonCommercial-Share Alike 3.0 Unported License. 